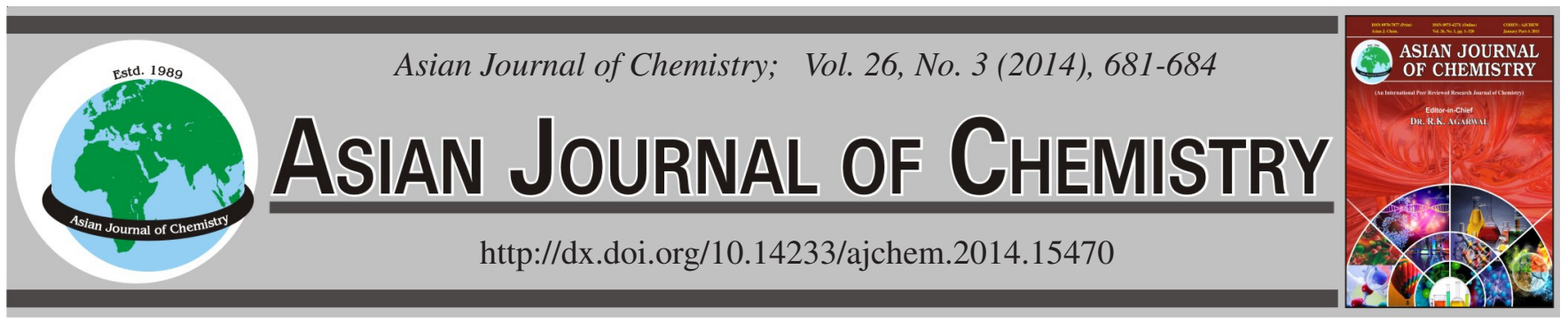

\title{
Synthesis, Thermal and Magnetic Behaviour of Monohydrated Cadmium Selenium(IV) Bromine(V) Oxide $\left[\mathrm{Cd}_{3} \mathrm{Se}_{2} \mathrm{Br}_{2} \mathrm{O}_{12} \cdot \mathrm{H}_{2} \mathrm{O}\right]$
}

\author{
Faiz RabBani $^{1,2, *}$, Humayun Ajaz $^{1}$ and K.A. Bhatti ${ }^{3}$
}

${ }^{1}$ Department of Chemistry, University of Engineering and Technology, Lahore, Pakistan

${ }^{2}$ Department of Chemistry, COMSATS Institute of Information Technology, Abbottabad 22060, Pakistan

${ }^{3}$ Department of Physics, University of Engineering and Technology, Lahore, Pakistan

*Corresponding author: E-mail: faizqau@yahoo.com

Received: 12 March 2013;

Accepted: 21 August 2013;

Published online: 30 January 2014;

AJC-14614

The monohydrated white crystals of nano-material, cadmium selenium(IV) bromine(V) oxide formulated as $\mathrm{Cd}_{3} \mathrm{Se}_{2} \mathrm{Br}_{2} \mathrm{O}_{12} \cdot \mathrm{H}_{2} \mathrm{O}$, were obtained at $450{ }^{\circ} \mathrm{C}$. The morphology and elemental analysis of the material were investigated by scanning electron microscopy and energy dispersive X-rays analysis. The new phase was confirmed through unique patterns of powder X-ray diffraction (PXRD) and characteristic melting point. The decomposition temperature and thermal behaviour of the product was studied using differential scanning colorimeter attached with thermal gravimetric analyzer. The bond vibrations and magnetic measurements were performed using fourier transform infra-red spectrophotometer and vibrating sample magnetometer respectively.

Keywords: Composite Materials, EDAX, DSC, FT/IR, $\mathrm{Cd}_{3} \mathrm{Se}_{2} \mathrm{Br}_{2} \mathrm{O}_{12} \cdot \mathrm{H}_{2} \mathrm{O}$.

L - - - - - - - - - - - - - - - - - - - - - - - -

\section{INTRODUCTION}

For few years, a strategy for the synthesis of novel inorganic composites with low-dimensional structure (1D or 2D arrangements) of $d$-block metal cations has been developed due to variety of its unusual magnetic properties like for memory devices ${ }^{1}$. A number of such new composites have recently been prepared by using chalcogen cations (e.g., $\mathrm{Te}^{4+}$, $\left.\mathrm{Se}^{4+}\right)^{2-8}$. Interesting properties of these materials like second harmonic generation $(\mathrm{SHG})^{9-12}$ and spin modulation ${ }^{13}$ have been observed.

As far as the Cd-X-Ch-O [where $\mathrm{X}=$ halogen $(\mathrm{Cl}, \mathrm{Br})$ cation, $\mathrm{Ch}=\mathrm{Te}, \mathrm{Se}$ ] system is concerned, no cadmium system with selenium containing halogen cations has been yet reported and a few cadmium tellurite halides have been found in literature i.e., $\left[\mathrm{Cd}_{2}\left(\mathrm{Te}_{6} \mathrm{O}_{13}\right)\right]\left[\mathrm{Cd}_{2} \mathrm{Cl}_{6}\right]$ and $\mathrm{Cd}_{7} \mathrm{Cl}_{8}\left(\mathrm{Te}_{7} \mathrm{O}_{17}\right)^{14}$. The aim of this research is focused to study a system containing both cadmium and selenium ions with halogen cation. The present work reports on the synthesis of novel magnetic material by solid state method and its characterization by SEM, EDX, XRD, DSC, TGA, IR and VSM respectively. The title compound contains selenium with +4 and bromine having +5 oxidation states that distinguishes it from reported systems.

\section{EXPERIMENTAL}

The reactants as $\mathrm{SeO}_{2}$ and $\mathrm{CdBr}_{2}$ (BDH Chemicals) of analytical grade (purity $>99 \%$ ) were used for the synthesis.
The surface morphology and composition of the synthesized nano-material were performed employing scanning electron microscope \{S 3700N, HITACHI, Japan $\}$ equipped with an energy dispersive analysis of X-rays spectrometer \{HORIBA, Japan $\}$ using point analysis method. X-ray diffraction patterns were obtained by using powder X-ray diffractometer (D8Discover, Bruker, Germany). Ni-filter and $\mathrm{Cu}-\mathrm{K}_{\alpha}$ radiations $(\lambda=1.54060 \AA)$ were used with scan speed $2 \%$ min at room temperature. Thermal analyses of the obtained product were performed using Differential Scanning Colorimeter attached with Thermal Gravimetric Analyzer \{SDT-Q600, TA Instrument, USA $\}$. Fourier Transform Infra-Red spectrophotometer \{FTIR-4100, JASCO-CE, PerkinElmer, UK\} and Vibrating Sample Magnetometer (Lakeshore's 7407) were used to study the vibrational and magnetic measurements of the material.

Preparation of $\left[\mathrm{Cd}_{3} \mathrm{Se}_{2} \mathrm{Br}_{2} \mathrm{O}_{12} \cdot \mathrm{H}_{2} \mathrm{O}\right]$ : Hydrated white crystals of the title compound were prepared via solid state technique in a muffle furnace. The starting materials, $0.2 \mathrm{~g}$ ( $1 \mathrm{mmol}) \mathrm{CdBr}_{2}$ and $0.074 \mathrm{~g}(0.67 \mathrm{mmol}) \mathrm{SeO}_{2}$ were mixed in agate mortar with a non-stoichiometric ratio 1/5:1 and placed in a ceramic crucible which was further treated in an electronically controlled muffle furnace at $450{ }^{\circ} \mathrm{C}$ for $170 \mathrm{~h}$. It was then cooled to room temperature at the rate of $5{ }^{\circ} \mathrm{C} / \mathrm{h}$. The obtained crystals was washed with acetone (Merck) and dried. Formula weight of the above composite was calculated using Sheffield Chem Puter ${ }^{15}$ to be 865.04 amu. 


\section{RESULTS AND DISCUSSION}

In SEM graph (Fig. 1), the material $\left(\mathrm{Cd}_{3} \mathrm{Se}_{2} \mathrm{Br}_{2} \mathrm{O}_{12} \cdot \mathrm{H}_{2} \mathrm{O}\right)$ clearly indicates a crystalline in nature which found to be in the different shapes. e.g. rod, bulky, particle like etc. The particulate size is found in the range of nanometers to micrometers which is also supported by powder-XRD results.

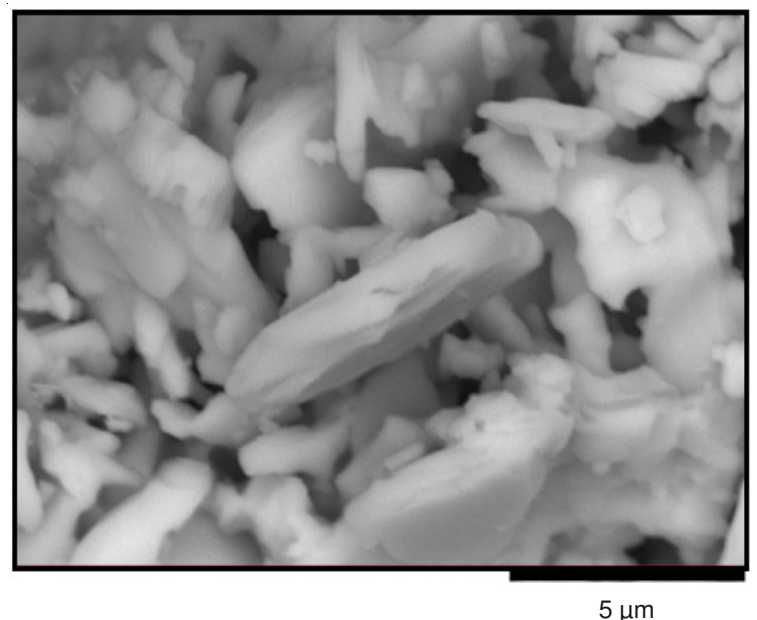

Fig. 1. SEM of $\mathrm{Cd}_{3} \mathrm{Se}_{2} \mathrm{Br}_{2} \mathrm{O}_{12} \cdot \mathrm{H}_{2} \mathrm{O}$

Energy dispersive $\mathrm{X}$-ray analysis: The EDAX spectrum of $\mathrm{Cd}_{3} \mathrm{Se}_{2} \mathrm{Br}_{2} \mathrm{O}_{12} \cdot \mathrm{H}_{2} \mathrm{O}$ (Fig. 2) is the plot of data between the relative intensity $\left(\mathrm{I}_{\text {rel }}\right)$ as ordinate and X-ray energy $(\mathrm{KeV})$ as abscissa. This spectrum insures the presence of all the elements ( $\mathrm{Cd}, \mathrm{Br}, \mathrm{Se}, \mathrm{O}$ ) in the $\mathrm{Cd}_{3} \mathrm{Se}_{2} \mathrm{Br}_{2} \mathrm{O}_{12} \cdot \mathrm{H}_{2} \mathrm{O}$. A comparison of atomic $\%$ between calculated (using the Sheffield ChemPuter ${ }^{15}$ ) and found results was given as

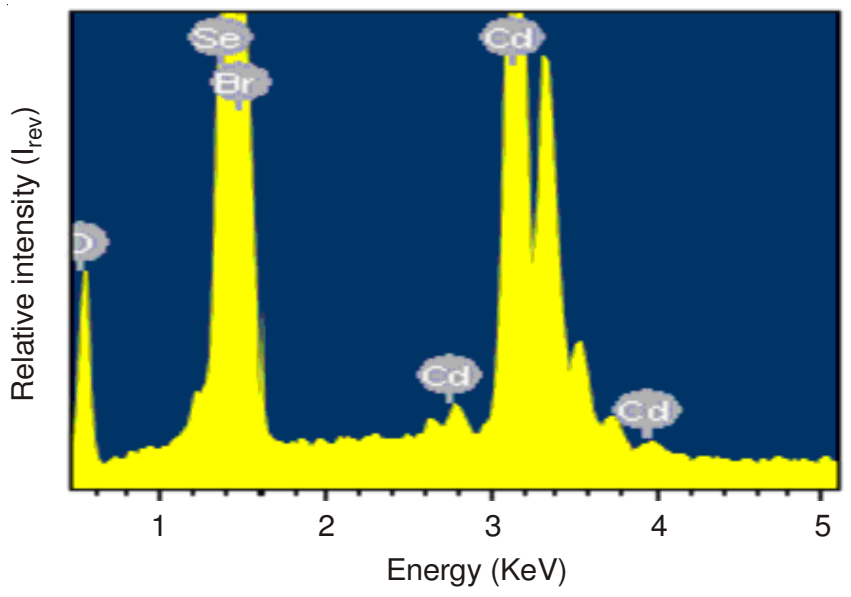

Fig. 2. EDAX analysis of $\mathrm{Cd}_{3} \mathrm{Se}_{2} \mathrm{Br}_{2} \mathrm{O}_{12} \cdot \mathrm{H}_{2} \mathrm{O}$ showing the presence of the constituting elements $(\mathrm{Cd}, \mathrm{Se}, \mathrm{Br}$ and $\mathrm{O})$

Atomic \%: element-calculated (found) Cd-15(15.48) / Se-10(10.34) / Br-10(9.88) / O- 65(64.30). The values showed that formula unit of the product is $\mathrm{Cd}_{3} \mathrm{Se}_{2} \mathrm{Br}_{2} \mathrm{O}_{12} \cdot \mathrm{H}_{2} \mathrm{O}$.

Powder X-ray diffraction analysis: For the $\mathrm{X}$-ray powder diffraction analysis, product is grinded and placed on the sample holder of the powder X-ray diffractometer (D8-Discover, Bruker, Germany) and measured with $2 \theta /^{\circ}=15$ to 90 for almost $30 \mathrm{~min}$.

The powder pattern of $\mathrm{Cd}_{3} \mathrm{Se}_{2} \mathrm{Br}_{2} \mathrm{O}_{12} \cdot \mathrm{H}_{2} \mathrm{O}$ (Fig. 3) reveals that the peaks at $2 \theta /{ }^{\circ}=20.285,21.722,23.143,25.152,31.101$,
$32.416,34.200,36.937,38.790,44.415,44.752,47.315$, $48.200,50.606,52.102,58.056,63.408,67.641$ and 77.875 are distinct and belong to the title compound where as peaks at $2 \theta /{ }^{\circ}=29.981$ and 33.594 correlate with the $\mathrm{Cd}_{3} \mathrm{Se}_{4} \mathrm{O}_{11}$ (confirmed by search match procedure). The data obtained from PXRD pattern of $\mathrm{Cd}_{3} \mathrm{Se}_{2} \mathrm{Br}_{2} \mathrm{O}_{12} \cdot \mathrm{H}_{2} \mathrm{O}$ (Fig. 3) is given in Table-1. The graphical representation of various PXRD parameters Vs $2 \theta /{ }^{\circ}$ is given in Fig. 4. The grain size, dislocation line density and strain of the heated samples were calculated by using the following formulas,

$$
\text { Grain size }(D)=0.9 \lambda / \beta \cos \theta^{16}
$$

where $\lambda=$ wavelength of the X-rays used (1.5406 $\AA$ ), $\beta=$ value of $1 / 2$ FWHM and $\theta=$ Bragg's angle.

Dislocation line density $(\delta)=1 / \mathrm{D}^{2},{ }^{17}$

where $\mathrm{D}=$ grain size

$$
\text { Strain }(S)=0.9 \lambda / 4 \mathrm{D}^{18}
$$

where $\mathrm{D}=$ grain size, $\lambda=$ wavelength of the $\mathrm{X}$-rays used $(1.5406 \AA)$

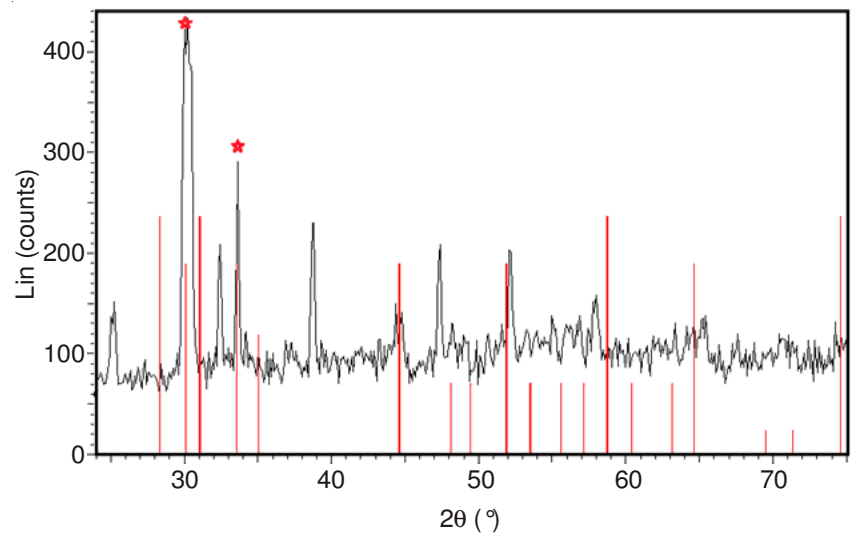

Fig. 3. PXRD diffractogram of $\mathrm{Cd}_{3} \mathrm{Se}_{2} \mathrm{Br}_{2} \mathrm{O}_{12} \cdot \mathrm{H}_{2} \mathrm{O}$ in comparison to that of $\mathrm{Cd}_{3} \mathrm{Se}_{4} \mathrm{O}_{11}$ (red lines)

Fig. 4 indicates that the range of grain size lies between $42.96 \mathrm{~nm}\left(\right.$ at $\left.2 \theta /^{\circ}=25.14\right)$ to $502.53 \mathrm{~nm}\left(\right.$ at $\left.2 \theta /^{\circ}=66.89^{\circ}\right)$ as shown in Table-1. As the particulate sizes lies in nanometer range, also supported by SEM results which shows the growth of nano particles employing solid state method.

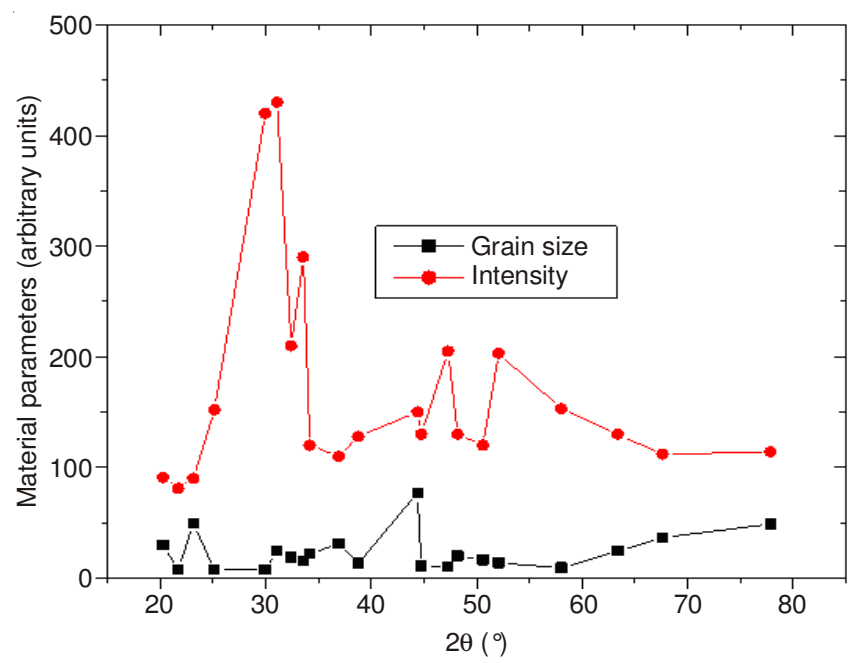

Fig. 4. Graphical representation of material parameters (intensity and grain size) versus $2 \theta\left(^{\circ}\right)$ (obtained from the PXRD analysis of $\mathrm{Cd}_{3} \mathrm{Se}_{2} \mathrm{Br}_{2} \mathrm{O}_{12} \cdot \mathrm{H}_{2} \mathrm{O}$ ) 
Fig. 4 also shows that there are decreasing and increasing trends in the grain size which may be due to the re-arrangement of the particles ${ }^{19}$. At elevated temperature $\left(450^{\circ} \mathrm{C}\right)$, during the growth of nano material, these variations may arise due to nucleation of smaller particles and thermal stresses which are also correlated with SEM graph (Fig. 1). The size of product may also depend upon the hardness of the material and the recovery processes ${ }^{20}$. Intensity changes follow a trend of exponential decay as shown in Fig. 4, which is due to change in orientation of particles as well as variation in scattering of crystals after long heat treatment of titled compound ${ }^{21}$. The larger variations in intensities of the diffracted X-rays may be due to crystal imperfections, non uniform strain, diffraction, thermal stresses, lattice vibrations of atoms ${ }^{15}$ and texture effects $^{22}$. After a long time heating $\left(450{ }^{\circ} \mathrm{C}\right.$ for $\left.170 \mathrm{~h}\right)$, the small variations in d-spacing, dislocation density and strains are observed (Table-1) due to the polygonization at this high temperature ${ }^{23}$.

\begin{tabular}{|c|c|c|c|c|c|}
\hline \multicolumn{6}{|c|}{$\begin{array}{c}\text { TABLE-1 } \\
\text { MATERIAL PARAMETERS (GRAIN SIZE, DISLOCATION } \\
\text { DENSITY AND STRAIN) CALCULATED ON THE BASIS OF } \\
\text { INTENSITY AND } 2 \theta\left(^{\circ}\right)(\text { OBTAINED BY THE X-RAY POWDER } \\
\text { DIFFRACTION ANALYSIS) }\end{array}$} \\
\hline $2 \theta\left(^{\circ}\right)$ & $\begin{array}{c}\text { d- } \\
\text { spac } \\
\text {-ing } \\
(\AA)\end{array}$ & $\begin{array}{c}\text { Grainsize } \\
(\mathrm{nm}) \mathrm{D}= \\
0.95 / \mathrm{B} \cos \theta\end{array}$ & $\begin{array}{c}\text { Dislocation } \\
\text { Density = } \\
1 / 2 \mathrm{D} \\
\left(\text { lines } / \mathrm{cm}^{2}\right)\end{array}$ & $\begin{array}{c}\text { Strain = } \\
.90 / 4 \mathrm{D} \\
\left(\text { lines }^{-2}\right. \\
\left.\mathrm{cm}^{-4}\right)\end{array}$ & $\begin{array}{l}\text { Intensity } \\
\text { (Counts) }\end{array}$ \\
\hline 20.285 & 0.05 & 29.73358 & 0.02591 & 0.01166 & 91 \\
\hline 21.722 & 0.2 & 7.456504 & 0.1033 & 0.04648 & 81 \\
\hline 23.143 & 0.03 & 49.776786 & 0.01547 & 6.9638 & 90 \\
\hline 25.152 & 0.2 & 7.502722 & 0.1026 & 0.0462 & 152 \\
\hline 29.981 & 0.2 & 7.579752 & 0.1016 & 0.04573 & 420 \\
\hline 31.101 & 0.1 & 24.387698 & 0.03158 & 0.01421 & 430 \\
\hline 32.416 & 0.08 & 18.764508 & 0.04105 & 0.01847 & 210 \\
\hline 33.594 & 0.1 & 15.25194 & 0.0505 & 0.02272 & 290 \\
\hline 34.2 & 0.07 & 21.845708 & 0.03526 & 0.01586 & 120 \\
\hline 36.937 & 0.05 & 31.135526 & 0.02474 & 0.01113 & 110 \\
\hline 38.79 & 0.12 & 13.310784 & 0.05787 & 0.02604 & 128 \\
\hline 44.415 & 0.02 & 77.03 & 0.01 & 0.0045 & 150 \\
\hline 44.752 & 0.15 & 10.522298 & 0.07321 & 0.03294 & 130 \\
\hline 47.315 & 0.16 & 10.029306 & 0.0768 & 0.03237 & 205 \\
\hline 48.2 & 0.08 & 20.043206 & 0.03843 & 0.01729 & 130 \\
\hline 50.606 & 0.1 & 16.268736 & 0.04735 & 0.02131 & 120 \\
\hline 52.102 & 0.12 & 13.55728 & 0.05682 & 0.02557 & 203 \\
\hline 58.056 & 0.18 & 9.32063 & 0.08264 & 0.03719 & 153 \\
\hline 63.408 & 0.07 & 24.387698 & 0.03158 & 0.01421 & 130 \\
\hline 67.641 & 0.05 & 36.58925 & 0.02105 & 9.4736 & 112 \\
\hline 77.875 & 0.04 & 48.790802 & 0.01579 & 7.1045 & 114 \\
\hline
\end{tabular}

Differential scanning colorimetric analysis: The DSC analysis shows that material melts at $533^{\circ} \mathrm{C}$. This characteristic melting point confirms the formation of new phase.

Thermal gravimetric analysis: The synthesized product is stable at room temperature. The theoretical weight loss $2.04 \%$ is in good agreement with observed $2.05 \%$ that confirms the removal of one water molecule at $100{ }^{\circ} \mathrm{C}$. The thermal decomposition of material may be described in two steps. In the first step, one molecule of $\mathrm{SeO}_{2}$ remove at $533^{\circ} \mathrm{C}$ followed the second molecule of $\mathrm{SeO}_{2}$ at $643{ }^{\circ} \mathrm{C}$ in second step. The theoretical weight loss for two $\mathrm{SeO}_{2}$ molecules is $26 \%$ but observed weight loss is $33 \%$ which shows that half molecule of unreacted $\mathrm{SeO}_{2}$ may also be removed.
Fourier transform infrared analysis: FTIR spectrum was obtained in the range of $4000-350 \mathrm{~cm}^{-1}$ which shows no absorption has been occurred in the region of $4000-850 \mathrm{~cm}^{-1}$ but absorbtion peaks are observed in the range $850-400 \mathrm{~cm}^{-1}$ (Fig. 5). IR absorption band $828 \mathrm{~cm}^{-1}$ assigned to the $\mathrm{v}(\mathrm{Se}-\mathrm{O})$ vibrations as reported for $\mathrm{Sr}_{2} \mathrm{Cu}\left(\mathrm{SeO}_{3}\right)_{2} \mathrm{Cl}_{2}{ }^{24}$ and $\mathrm{SrCu}_{2}\left(\mathrm{SeO}_{3}\right)_{2} \mathrm{Cl}_{2}{ }_{2}^{25}$. The absorption band $468 \mathrm{~cm}^{-1}$ is assigned to the $\delta(\mathrm{Br}-\mathrm{O})$ vibrations as reported ${ }^{26}$ which confirms the presence of bonds (Br-O and $\mathrm{Se}-\mathrm{O})$ in the product.

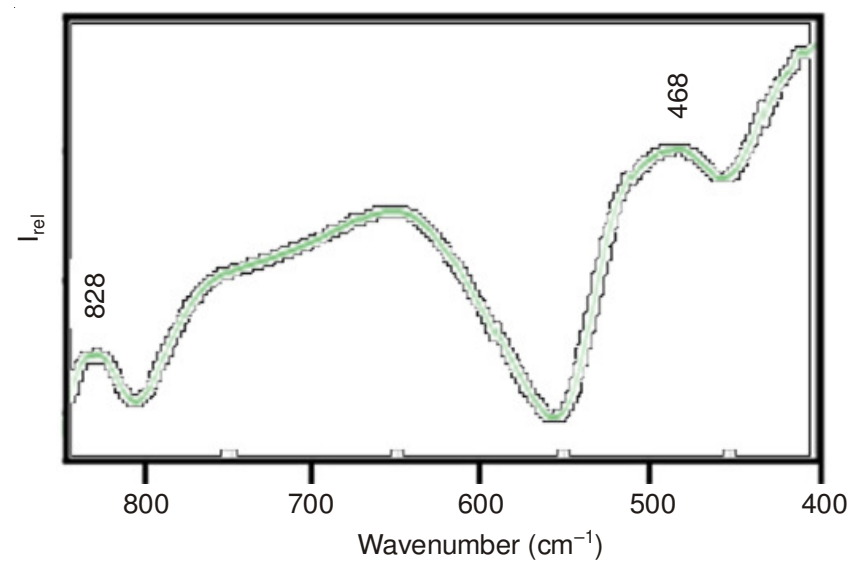

Fig. 5. Infrared spectrum of $\mathrm{Cd}_{3} \mathrm{Se}_{2} \mathrm{Br}_{2} \mathrm{O}_{12} \cdot \mathrm{xH}_{2} \mathrm{O}$

Magnetic analysis: The magnetic analysis of the product was measured by using vibrating sample magnetometer (VSM). The magnetic spectrum is a plot between magnetic moment (emu) versus magnetic field $(\mathrm{G})$ for clean material at room temperature (Fig. 6). The magnetic coercivity of compound is strongly dependent upon its microstructure ${ }^{27}$. The presence of magnetic domains is due to the nanoparticles as in case of nanosize, magnetization can randomly flip direction under the effect of temperature ${ }^{28}$. The magnetic retentivity $(\mathrm{Mr})$ and intrinsic coercivity (Hci) of the sample were calculated through hysterisis which are to be $605.68 \times 10^{-6} \mathrm{emu} / \mathrm{cm}^{3}$ and 54.157 $\mathrm{G}$ respectively. Similarly, magnetization saturation $(10.473 \times$ $\left.10^{-3} \mathrm{emu} / \mathrm{cm}^{3}\right)$, curve squareness $\left(57.832 \times 10^{-3}\right)$ and total area related to energy loss (8.0018 ergs) were also calculated through this analysis. The above analysis confirms that the obtained material is soft ferromagnetic in nature.

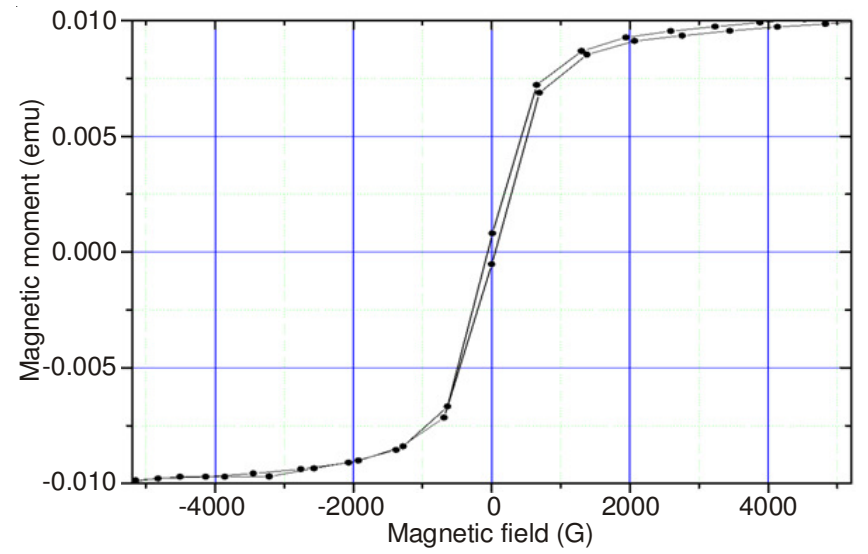

Fig. 8. Magnetic measurement of $\mathrm{Cd}_{3} \mathrm{Se}_{2} \mathrm{Br}_{2} \mathrm{O}_{12} \cdot \mathrm{H}_{2} \mathrm{O}$ (Graphic representation of the change in magnetic moment with the change in the applied magnetic field) 
Scope and limitations: The transition metals selenites containing halogens sometimes having pours in their structures. If so then it may be used for gas absorption measurements and photo catalytic properties where water molecules split into hydrogen and oxygen. As the reactants are health hazardous so one should be careful during their use.

\section{Conclusion}

The monohydrated stable new material represented as $\mathrm{Cd}_{3} \mathrm{Se}_{2} \mathrm{Br}_{2} \mathrm{O}_{12} \cdot \mathrm{H}_{2} \mathrm{O}$, is crystalline in nature and exists in the range of $\mathrm{nm}$ to $\mu \mathrm{m}$ particulate size that has been started to decompose at $533{ }^{\circ} \mathrm{C}$. The presence of all the elements $(\mathrm{Cd}$, $\mathrm{Se}, \mathrm{Br}$ and $\mathrm{O}$ ), their stoichiometric ratio and bonding between them have been assured. The decomposition behavior of soft ferromagnetic product has also been studied. Due to small size of crystals, it can be structurally characterized using transmission electron microscopy. This work further leads to the syntheses of a number of noval compounds having same composition containing other transition metals especially Co, Fe and $\mathrm{Zn}$.

\section{ACKNOWLEDGEMENTS}

The authors gratefully acknowledged the support from Higher Education Pakistan (HEC) of Pakistan for Indigenous PhD scholarship program with its financial support. Faiz Rabbani also thank the PCSIR, Lahore and Prof. Dr. Shahzad Naseem (Punjab University) for the characterization of material.

\section{REFERENCES}

1. B.A. El-Sayed, A.A.A. Emara, F.S.M.Abd El-Hameed and S.M. Shaaban, Mater. Lett., 27, 247 (1996).

2. M. Johnsson, K.W. Törnroos, P. Lemmens and P. Millet, Chem. Mater., 15, 68 (2003).

3. R. Becker and M. Johnsson, J. Solid State Chem., 180, 1750 (2007).

4. R. Becker, M. Johnsson, R.K. Kremer and P. Lemmens, Solid State Sci., 5, 1411 (2003).

5. R. Becker, M. Johnsson, R. Kremer and P. Lemmens, J. Solid State Chem., 178, 2024 (2005)
6. R. Becker, H. Berger, M. Johnsson, M. Prester, Z. Marohnic, M. Miljak and M. Herak, J. Solid State Chem., 179, 836 (2006).

7. R. Takagi, M. Johnsson, V. Gnezdilov, R.K. Kremer, W. Brenig and P. Lemmens, Phys. Rev., B74 014413, (2006).

8. Z. Mayerova', M. Johnsson and S. Lidin, Angew. Chem. Int. Ed., 45, 5602 (2006).

9. Y.L. Shen, J.G. Mao and H.L. Jiang, J. Solid State Chem., 178, 2942 (2005).

10. R.T. Hart, K.-M. Ok, P.S. Halasyamani and J.W. Zwanziger, Appl. Phys. Lett., 85, 938 (2004).

11. M.G. Johnston and W.T.A. Harrison, J. Solid State Chem., 177, 4680 (2004).

12. M.A. Cooper and F.C. Hawthorne, Can. Mineral., 39, 797 (2001).

13. O. Zaharko, M. Pregelj, D. Arcon, P.J. Brown, D. Chernyshov, U. Stuhr and H. Berger, J. Phys. Conf. Ser., 211, 012002 (2010).

14. H. L. Jiang and J.G. Mao, Inorg. Chem., 45, 717 (2006).

15. http://winter.group.shef.ac.uk/chemputer/percent.html(04/05/2011, 08:35am)

16. E. Mirica, G. Kowach, P. Evans and H. Du, Cryst. Growth Des., 4, 147 (2004).

17. M.S. Rafique, M. Khaleeq-ur-Rahman, S. Saif-ur-Rehman, M.S. Anjum, K.A. Anwar, S. Bhatti, Saeed and M.S. Awan, Vaccum, 82, 1233 (2008).

18. A. Latif, Ph.D. Thesis, The Diagnostic and Analysis of Optical, Thermal and Electrical Properties of Laser Ablated Materials, Department of Physics, University of Engineering and Technology, Lahore, Pakistan (2011).

19. N. Matsunami, O. Fukuoka, M. Tazawa and M. Sataka, Surf. Coat. Technol., 196, 50 (2005).

20. W.F. Smith, Principles of Material Science and Engineering, McGraw Hill, Tokyo, edn 2 (1990).

21. M. Khaleeq-ur-Rahman, K.A. Bhatti, M.S. Rafique, A. Latif, P. Lee and S. Mahmood, Laser Phys., 17, 1382 (2007).

22. H. Ajaz, H.-J. Deiseroth, M. Schlosser and F. Rabbani, Synth. React. Inorg. Metal-Org. Nano-Metal Chem., 39, 209 (2009).

23. A. Latif, M. Khaleeq-Ur-Rahman, M.S. Rafique, K.A. Bhatti and M. Imran, Radiat. Effects Defects Solids, 164, 68 (2009).

24. P.S. Berdonosov, A.V. Olenev and V.A. Dolgikh, J. Solid State Chem., 182, 2368 (2009).

25. P.S. Berdonosov, A.V. Olenev, A.N. Kuznetsov and V.A. Dolgikh, J. Solid State Chem., 182, 77 (2009).

26. A. Abbasi and M.Y. Skripkin, J. Sci. Univ. Tehran, 33, 1 (2007).

27. C. Jin, R. Aggarwal, W. Wei, S. Nori, D. Kumar, D. Ponarin, A.I. Smirnov, J. Narayan and R.J. Narayan, Metallurg. Mater. Trans. A, 42A, 3250 (2011)

28. S. Riaz, S. Naseem and Y.B. Xu, J. Sol-Gel Sci. Technol., 59, 584 (2011). 